\title{
Resilience in pregnant women with pre-gestational diabetes during COVID-19 pandemic: the experience of the Papa Giovanni XXIII Hospital in Bergamo, Italy
}

\author{
Alessandro Roberto Dodesini ${ }^{1}$ (1) $\cdot$ Anna Caffi ${ }^{2} \cdot$ Maria Simonetta Spada ${ }^{2} \cdot$ Roberto Trevisan $^{1}$
}

Received: 28 September 2020 / Accepted: 16 November 2020 / Published online: 25 November 2020

(c) Springer-Verlag Italia S.r.l., part of Springer Nature 2020

A novel coronavirus, named COVID-19, quickly spreads from China to the world. The pneumonia caused by COVID19 (SARS-CoV-2) is highly contagious and frequently fatal. Its morbidity and socioeconomic impact have necessitated drastic measures across all continents, including nationwide lockdowns. Recent studies investigated the impact of the fear of COVID-19 pandemic and related lockdown on the psychosocial well-being of general population, with evidence of an increase in anxiety symptoms, depression and adaptation and post-traumatic stress disorder [1]. Psychological resilience is the ability to mentally or emotionally cope with a crisis or to return to pre-crisis status quickly [2]. The identification of interventions or conditions capable of increasing resilience are urgently needed. Few data are available for pregnant women who are one of the most critical population groups with a need to take additional precautions against SARS-CoV-2. In this context, the presence of pre-gestational diabetes mellitus [3] leads to a high-risk pregnancy requiring frequent monitoring and adjustment of medications to prevent maternal and fetal complications.

Our aim was to explore not only the impact of COVID19 pandemic with related lockdown measures in pregnant women with pre-gestational diabetes mellitus, but also whether pregnancy supports their resilience to the pandemic. We administered two questionnaires in self-report mode to all (COVID-19 swab negative) 14 women with pre-gestational diabetes (nine women had Type 1 and five Type 2 Diabetes: (mean \pm SD) age was $35 \pm 5$ years; BMI 29, $1 \pm$

Managed by Antonio Secchi.

Alessandro Roberto Dodesini

adodesini@asst-pg23.it

$1 \quad$ Endocrinology and Diabetes Unit, ASST Papa Giovanni XXIII, Bergamo, Italy

2 Psychology Unit, ASST Papa Giovanni XXIII, Bergamo, Italy
$5,6 \mathrm{Kg} / \mathrm{m}^{2}$; A1c $43 \pm 8 \mathrm{mmol} / \mathrm{mol}$; diabetes duration $10 \pm$ 8 years; gestational age $25 \pm 5$ weeks) attending Diabetes and Pregnancy Clinic of the Papa Giovanni XXIII Hospital in Bergamo from March 21 to May 2, 2020. The first questionnaire was related to their perception of health and quality of life (Short Form Health Survey 36, SF-36) [4] and the second to resilience (Resilience Scale for Adults, RSA) [5]. The Short Form Health Survey 36 (SF-36) is a short questionnaire (36 items) evaluating eight dimensions: physical and social functioning, limitations due to physical and emotional problems, mental health, energy/vitality, pain and perception of general health. The RSA was chosen because it does not only take in to account individual psychological characteristics, but also examines specific subscales measuring family and external support, two basic elements of resilience.

None of the women had significant comorbidities other than diabetes and an average high education level. Studies not involving drugs do not require ethics committee approval and written informed consent in our institution.

SF-36 questionnaire showed that the great majority of women had a normal score for all dimensions (Table 1). Only two women had lower score value of physical functioning, four had limitations due to physical problems and one a lower perception of general health. All women had normal or above normal score in mental health dimension. Table 2 shows that only one subject had poor resilience with total mean scores lower than normal. In particular, the "social resources" subscale was the factor with the higher average, while the "self-perception" factor was the one with the lowest score.

Despite the small sample size, our study demonstrated a low impact of COVID-19 pandemic and its lockdown period in this high-risk population of pregnant women. Although the major limit of our study is the lack of a control group (i.e., pregnant women without diabetes), we suggest that pregnancy "per se" may constitute a protective factor helping diabetic women to take care of themselves and to 
Table 1 Numbers of women with pregestational diabetes with below normal, normal and abnormal scores for the eight subscales of SF-36 questionnarie

\begin{tabular}{llll}
\hline & Below normal & Normal & Above normal \\
\hline Physical functioning & 2 & 12 & 0 \\
Role-physical & 4 & 10 & 0 \\
Bodily pain & 0 & 14 & 0 \\
General health & 1 & 13 & 0 \\
Vitality & 0 & 14 & 0 \\
Social functioning & 0 & 14 & 0 \\
Role-emotional & 0 & 13 & 1 \\
Mental health & 0 & 12 & 2
\end{tabular}

For all eight subscales of SF-36, normality was defined by of a mean score \pm 2 SD of that of Italian Women of similar age.

\begin{tabular}{llllllll}
\hline & Social skills & $\begin{array}{l}\text { Planning } \\
\text { for the } \\
\text { future }\end{array}$ & Self-perception & $\begin{array}{l}\text { Family } \\
\text { coher- } \\
\text { ence }\end{array}$ & Social support & $\begin{array}{l}\text { Personal } \\
\text { structure }\end{array}$ & $\begin{array}{l}\text { Mean } \\
\text { total } \\
\text { scores }\end{array}$ \\
\hline Subject 1 & 3,67 & $\mathbf{2 , 2 5}$ & 3,33 & 3,50 & 3,14 & 3,50 & 3,27 \\
Subject 2 & $\mathbf{2 , 6 7}$ & 3,00 & 3,00 & 3,00 & 3,00 & 3,25 & $\mathbf{2 , 9 7}$ \\
Subject 3 & 4,00 & 3,50 & 3,83 & 4,33 & 4,00 & 4,75 & 4,06 \\
Subject 4 & $\mathbf{2 , 6 7}$ & 3,50 & 4,33 & 4,00 & 4,29 & 4,75 & 3,91 \\
Subject 5 & 4,33 & 4,75 & 4,33 & 4,17 & 4,86 & 4,75 & 4,52 \\
Subject 6 & 3,33 & 3,50 & 3,00 & 3,17 & 3,14 & 3,25 & 3,21 \\
Subject 7 & $\mathbf{2 , 8 3}$ & $\mathbf{2 , 7 5}$ & 3,17 & 3,00 & 3,43 & 3,00 & 3,06 \\
Subject 8 & 3,83 & 3,25 & 4,17 & 4,17 & 4,57 & 4,75 & 4,15 \\
Subject 9 & 4,17 & 4,50 & 4,33 & 4,33 & 4,43 & 4,75 & 4,39 \\
Subject 10 & 4,17 & 4,00 & 4,00 & 5,00 & 4,71 & 5,00 & 4,48 \\
Subject 11 & 3,00 & 3,75 & $\mathbf{2 , 6 7}$ & 3,33 & 3,57 & $\mathbf{2 , 5 0}$ & 3,15 \\
Subject 12 & $\mathbf{2 , 6 7}$ & 3,25 & 3,17 & $\mathbf{2 , 6 7}$ & 3,57 & 3,50 & 3,12 \\
Subject 13 & 4,00 & 3,00 & 4,33 & 3,33 & 4,29 & 4,00 & 3,88 \\
Subject 14 & 4,67 & 3,75 & 4,00 & 4,33 & 4,29 & 4,75 & 4,30 \\
Mean & 3,57 & 3,48 & 3,69 & 3,74 & 3,95 & 4,04 & 3,75 \\
SD & 0,70 & 0,66 & 0,61 & 0,68 & 0,63 & 0,84 & 0,59 \\
\hline
\end{tabular}

The cut-off for having a normal score for each of the 6 subdimensions was set $>2.99$

Bold represent the results under the cut-off
Table 2 Mean individual and total scores of 6 subdimensions of the Resilience Scale for Adult (RSA) in women with pregestational diabetes. perceive adequate social and family support. Larger observation studies in pregnant women with and without diabetes are needed to better evaluate pregnancy as a resilience component against COVID-19 pandemic. The presence of such protective resources could be of paramount importance of increasing resilience to counteract the documented negative outcomes on the psychic structure of the re-adaptation related to pandemic.

Acknowledgements The authors acknowledge all of the women who participated in the study.

Author contributions ARD designed and coordinated the study, wrote and revised the manuscript; $\mathrm{AC}$ enrolled patients and analyzed data;
MSS and RT edited and revised the manuscript. All authors have contributed to and approved the final version of the manuscript.

Funding Not applicable

\section{Compliance with ethical standards}

Conflicts of interest The authors declare that they have no conflict of interest.

Ethical approval In our institution studies not involving drugs do not require ethics committee approval and written informed consent. 


\section{References}

1. Talevi D, Socci V, Carai M et al (2020) Mental health outcomes of the CoViD-19 pandemic. Riv Psichiatr 55(3):137-144

2. Fletcher D, Sarkar M (2013) Psychological resilience: A review and critique of definitions, concepts, and theory. Eur Psychol 18:12-23

3. Scavini M, Secchi A (2019) Diabetes in pregnancy. Acta Diabetol 56(7):719-721

4. Ware JE Jr, Sherbourne CD (1992) The MOS 36-item short-form (SF-36) health survey SF. I. Conceptual framework and item selection. Med Care 30(6):473-83
5. Friborg O, Hjemdal O, Rosenvinge JH et al (2003) A new rating scale for adult resilience: what are the central protective resources behind healthy adjustment? Int J Methods Psychiatr Res 12(2):65-76

Publisher's Note Springer Nature remains neutral with regard to jurisdictional claims in published maps and institutional affiliations. 